\title{
Hygroscopic Salts and the Potential for Life on Mars
}

\author{
Alfonso F. Davila, Luis Gago Duport, ${ }^{2}$ Riccardo Melchiorri, ${ }^{3}$ Jochen Jänchen, ${ }^{4}$ \\ Sergio Valea, ${ }^{5}$ Asunción de los Rios, ${ }^{5}$ Alberto G. Fairén, Diedrich Möhlmann, \\ Christopher P. McKay, ${ }^{7}$ Carmen Ascaso, ${ }^{5}$ and Jacek Wierzchos ${ }^{5}$
}

\begin{abstract}
Hygroscopic salts have been detected in soils in the northern latitudes of Mars, and widespread chloride-bearing evaporitic deposits have been detected in the southern highlands. The deliquescence of hygroscopic minerals such as chloride salts could provide a local and transient source of liquid water that would be available for microorganisms on the surface. This is known to occur in the Atacama Desert, where massive halite evaporites have become a habitat for photosynthetic and heterotrophic microorganisms that take advantage of the deliquescence of the salt at certain relative humidity $(\mathrm{RH})$ levels. We modeled the climate conditions (RH and temperature) in a region on Mars with chloride-bearing evaporites, and modeled the evolution of the water activity $\left(a_{\mathrm{w}}\right)$ of the deliquescence solutions of three possible chloride salts (sodium chloride, calcium chloride, and magnesium chloride) as a function of temperature. We also studied the water absorption properties of the same salts as a function of RH. Our climate model results show that the RH in the region with chloride-bearing deposits on Mars often reaches the deliquescence points of all three salts, and the temperature reaches levels above their eutectic points seasonally, in the course of a martian year. The $a_{\mathrm{w}}$ of the deliquescence solutions increases with decreasing temperature due mainly to the precipitation of unstable phases, which removes ions from the solution. The deliquescence of sodium chloride results in transient solutions with $a_{\mathrm{w}}$ compatible with growth of terrestrial microorganisms down to $252 \mathrm{~K}$, whereas for calcium chloride and magnesium chloride it results in solutions with $a_{\mathrm{w}}$ below the known limits for growth at all temperatures. However, taking the limits of $a_{\mathrm{w}}$ used to define special regions on Mars, the deliquescence of calcium chloride deposits would allow for the propagation of terrestrial microorganisms at temperatures between 265 and $253 \mathrm{~K}$, and for metabolic activity (no growth) at temperatures between 253 and $233 \mathrm{~K}$. Key Words: Hygroscopic salts-Evaporites-Water activityTemperature-Endoliths-Atacama Desert-Deliquescence-Mars-Life. Astrobiology 10, 617-628.
\end{abstract}

\section{Introduction}

L IQUID WATER is the single most important requisite for life on Earth, and its search has driven the exploration of Mars for the past 30 years. Geomorphological and mineralogical evidence supports the idea that liquid water was stable on the martian surface in the past (i.e., Carr, 1996; Fairén et al., 2004, 2009; Squyres et al., 2004; Bibring et al., 2006; Mustard et al., 2008), but under current environmental conditions liquid water is not stable on the surface at large scales (i.e., Haberle et al., 2001), which reduces dramatically the potential for life near the surface. However, there are local processes that could allow for the occurrence of liquid water at smaller scales, at least transiently. One example is mineral deliquescence, which is a property of some minerals whereby at certain relative humidity $(\mathrm{RH})$ levels they spontaneously absorb water molecules and a liquid solution forms on the surface of their crystals (i.e., Tang et al., 1977). The RH at which deliquescence occurs is known as deliquescence relative humidity (DRH); each mineral has a characteristic DRH value (Table 1).

Hygroscopic minerals and deliquescence processes have long been postulated to occur on Mars (Clark, 1978). This has been confirmed recently by the Phoenix lander, with the detection of perchlorate in the soil (Hecht et al., 2009).

\footnotetext{
${ }^{1}$ SETI Institute, Mountain View, California, USA.

${ }^{2}$ Universidad de Vigo, Campus Lagoas Marcosende, Vigo, Spain.

${ }^{3}$ SRI International, Molecular Physics Laboratory, Physical Science Division, Menlo Park, California, USA.

${ }^{4}$ Technical University of Applied Sciences Wildau, Wildau, Germany.

${ }^{5}$ Instituto de Recursos Naturales, CCMA, CSIC, Madrid, Spain.

${ }^{6}$ DLR Institut für Planetenforschung, Berlin, Germany.

${ }^{7}$ NASA Ames Research Center, Moffett Field, California, USA.
} 
Table 1. Deliquescence Relative Humidity (DRH),

Water Activity $\left(a_{\mathrm{w}}\right)$, Eutectic Temperature $\left(T_{\mathrm{e}}\right)$ and Water Activity at the Eutectic $\left(a_{\text {we }}\right)$ for Three Saturated Chloride Salt Solutions

\begin{tabular}{lccccc}
\hline Salt & $D R H(\%)$ & $\mathrm{a}_{w}$ & $\mathrm{~T}_{e}(\mathrm{~K})$ & $\mathrm{a}_{\text {we }}$ & References \\
\hline $\mathrm{NaCl}$ & 75 & 0.75 & 252 & $0.82 *$ & Cohen et al., 1987 \\
$\mathrm{CaCl}_{2}$ & $28-31$ & 0.35 & 223 & $0.62 *$ & $\begin{array}{c}\text { Greenspan, 1977; } \\
\text { Cohen } \text { et al., 1987 }\end{array}$ \\
$\mathrm{MgCl}_{2}$ & 33 & 0.33 & 240 & $\mathrm{n} / \mathrm{a}$ & $\begin{array}{c}\text { Greenspan, 1977; } \\
\text { Cohen } \text { et al., 1987 }\end{array}$
\end{tabular}

*This study.

$\mathrm{n} / \mathrm{a}$, not available.

Chevrier et al. (2009) showed theoretically that perchlorate in these soils could deliquesce and form a transient liquid solution under present-day conditions. This has been confirmed experimentally (Zorzano et al., 2009) and is supported by the observation that small specks of soil on the Phoenix lander underwent physical changes that are interpreted to be the result of the deliquescence of perchlorate in the soil and the formation of a transient brine (Rennó et al., 2009). Thermodynamic arguments also support the idea that cryo-brines will form from the interaction of thin films of interfacial water and salt grains in the soil (Möhlmann, 2010). Additionally, there are other processes that favor the condensation of liquid water on the surface of salt crystals, even at RH below DRH. For example, Wise et al. (2008) showed that a significant amount of water is reversibly associated with substrate-supported sodium chloride particles at RH as low as $70 \%$. While these phenomena might not be significant at large scales, they could play an important role at the scale of microbial colonies (Möhlmann, 2008, 2010).
While perchlorate accounts for only $1 \%$ of the soil composition at the Phoenix site (Hecht et al., 2009), Osterloo et al. (2008) recently identified and mapped widespread deposits with a chloride salt component that resemble salt flats. These deposits are found in the southern hemisphere across the entire planet at latitudes between $-10^{\circ}$ and $-50^{\circ}$ (Figs. 1 and 2). The deposits have been interpreted as the result of brines formed in an evaporitic environment (Osterloo et al., 2008), either by evaporation of a large body of water or by capillary action in the soil that could draw salt-rich water toward the surface, where the water evaporates and the salt accumulates. Most chloride-bearing deposits are small in area $\left(<25 \mathrm{~km}^{2}\right)$ and commonly occur in topographic lows relative to the surrounding terrain (Fig. 2). The exact composition of the deposits is still unknown. However, the bright appearance of the deposits compared to the darker surrounding terrain, the deposits' irregular morphology with shoreline-like edges, the occasional presence of fluvial features that debouch directly into the deposits, and their occurrence in topographic lows support the evaporative origin of the deposits (Osterloo et al., 2008). Many chloride salts are hygroscopic, and their potential to deliquesce and form transient solutions makes them a candidate substrate that would allow for the occurrence of transient liquid water on Mars, even under the present-day climate.

The hypothesis that mineral deliquescence could sustain an active microbial ecosystem under extremely dry conditions is supported by recent studies conducted in the Atacama Desert, Chile. Geological and soil mineralogy data suggest that extreme arid conditions have persisted in the southern Atacama for 10-15 million years (Ericksen, 1983; Hartley et al., 2005; Clarke, 2006), which makes it one of the oldest, if not the oldest, desert on Earth. The Atacama Desert is also the driest terrestrial environment, with mean precip-

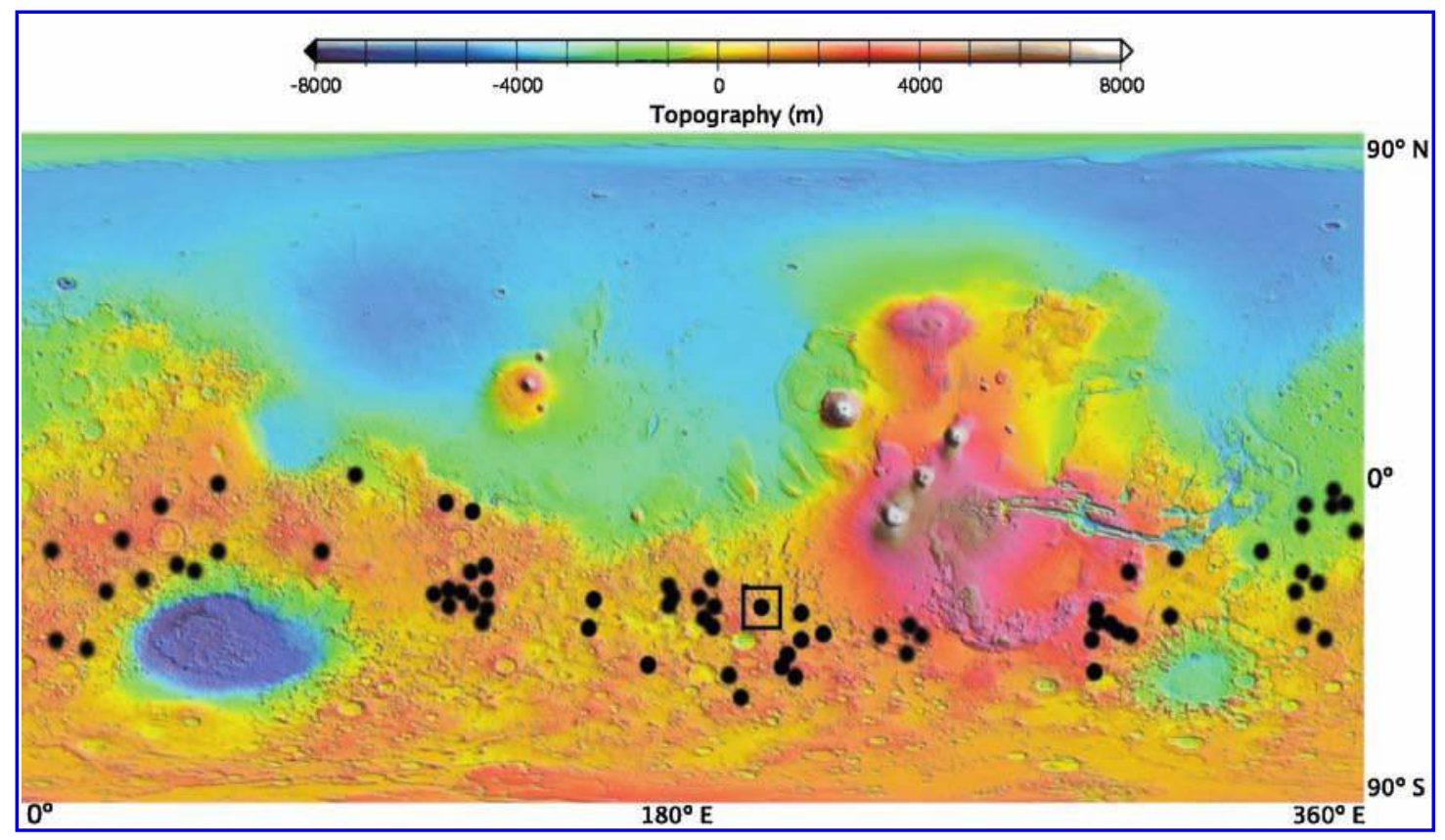

FIG. 1. Mars Orbiter Laser Altimeter (MOLA) map, showing the distribution of materials with a distinct spectral feature, interpreted to indicate the presence of chloride-bearing deposits (Osterloo et al., 2008). All the deposits occur in the southern highlands. Square indicates the location of the deposit shown in Fig. 2. Color images available online at www.liebertonline. com/ast. 


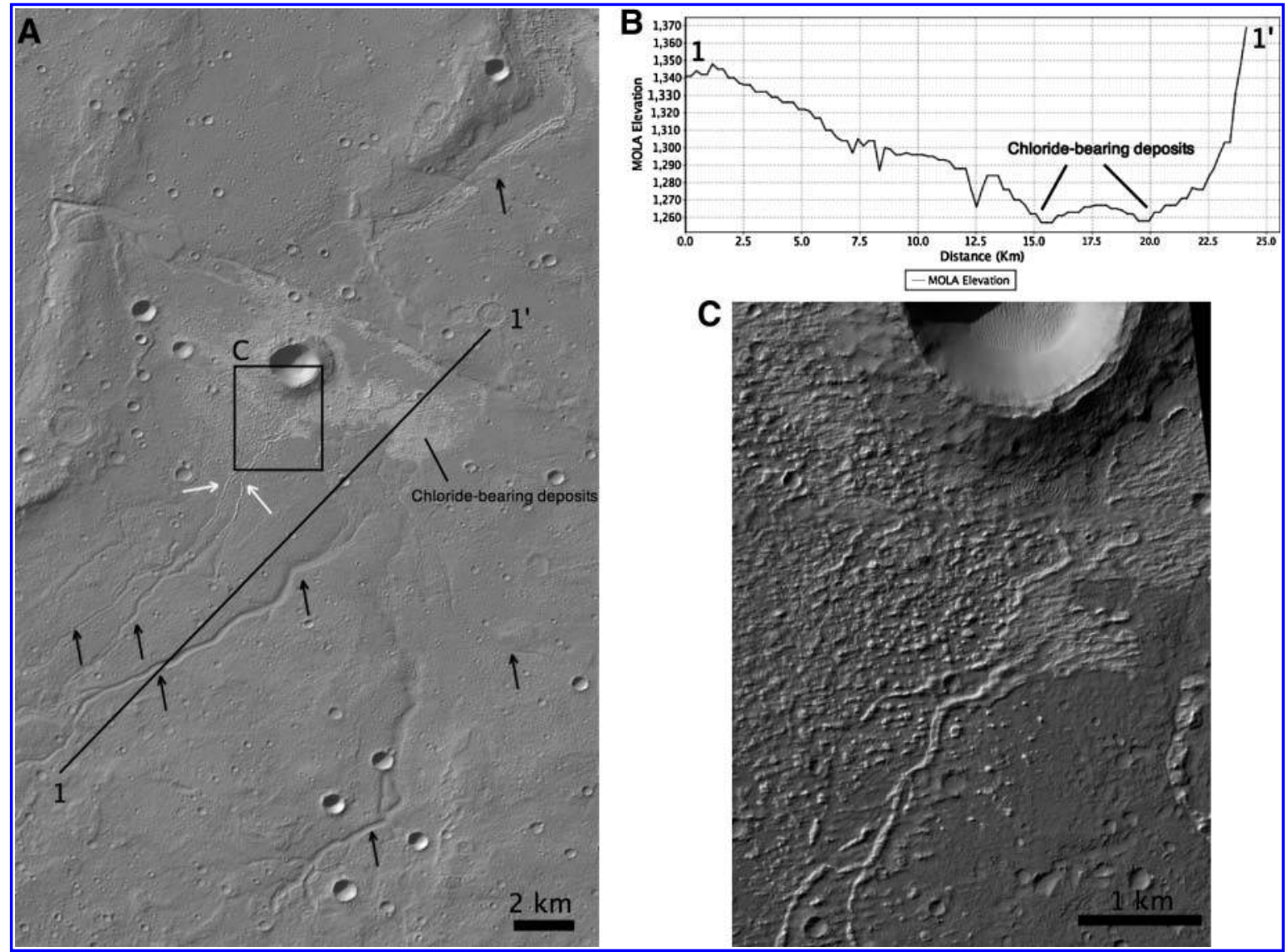

FIG. 2. (A) Putative chloride-bearing deposit in the southern highlands of Mars (see Fig. 1 for location). The deposit appears bright against the surrounding terrain. A system of fluvial channels (black arrows) can be seen to the south of the deposit, and they debouch directly into the deposit. The solid line represents the transect depicted in (B), showing the topographic relationships between the channels and the deposit. Note that the bright deposit occurs at the bottom of the basin, as expected in an evaporitic environment. (C) Some of the channels are inverted in their lower parts, close to the deposit [see also white arrows in (A)], and they form fan structures at their terminus.

itation rates of less than $1 \mathrm{~mm}$ over periods of several years (McKay et al., 2003). The extreme dryness has resulted in evaporitic deposits that share many similarities with the chloride-bearing deposits found on Mars (Bobst et al., 2001; Lowenstein et al., 2003). Wierzchos et al. (2006) recently discovered an active and diverse microbial ecosystem associated with the halite crusts that form these evaporites. Abundant colonies of photosynthetic cyanobacteria can be found $3-7 \mathrm{~mm}$ beneath the surface of the crusts distributed within pores and cracks between halite crystals (Wierzchos et al., 2006). With high-resolution $\mathrm{RH}$ and temperature (T) recordings, Davila et al. (2008) showed that, through mineral deliquescence, the photosynthetic microorganisms inside the crusts have access to liquid water even under the extreme dryness of the Atacama Desert. When the environmental RH increases above $75 \%$, which corresponds to the DRH of halite, a liquid brine forms in the interior of the crust, which can persist for several days. With this mechanism, the endoevaporitic microorganisms have access to liquid water when the conditions outside the crust are completely dry. The authors suggested that mineral deliquescence could explain why the halite crusts in the hyper-arid region of the desert are colonized by abundant phototrophs, while they are virtually absent in adjacent soils (Navarro-González et al.,
2003; Connon et al., 2007) as well as in hypolithic habitats (Warren-Rhodes et al., 2006).

We have analyzed the potential of salt flats on Mars to become a transient habitable environment, under present environmental conditions, due to mineral deliquescence. Here, we show the water absorption and deliquescence properties of three different salts (sodium chloride, calcium chloride and magnesium chloride) as a function of $\mathrm{RH}$ and $\mathrm{T}$, and present an analysis as to whether the water activity and the temperature of these deliquescence solutions fall within the known limits of biological activity for terrestrial microorganisms as a first-order approximation to assessing the habitability of chloride-bearing deposits on Mars. Finally, we estimate the $\mathrm{RH}$ and $T$ fluctuations throughout one martian year, in a region on Mars that contains chloride-bearing deposits (Fig. 2), to determine whether deliquescence can occur under current climate conditions.

\section{Methods}

\subsection{Gravimetric isotherm measurements and materials}

Water adsorption isotherms were measured gravimetrically in a high-vacuum apparatus consisting of a McBain 
quartz spring balance (sensitivity $4 \mathrm{mg} / \mathrm{mm}$ ) connected to a turbo molecular pump. The length change of the spring (because of the water sorption/desorption at a given vapor pressure) was determined with a cathetometer with a resolution of $10^{-2} \mathrm{~mm}$. The error of the adsorbed amount in $\mathrm{g}$ water/g adsorbent corresponds to $2-4 \%$. Each sample was placed in a small quartz basket and thermostated separately from the spring at the given measuring temperatures between 263 and $293 \mathrm{~K}$. The pressure of the water vapor was determined with MKS Baratron pressure heads of high sensitivity ranging from $10^{-5}$ to $10^{3}$ mbar. The equilibration time after dosing of a certain measuring point (time up to constancy of mass and pressure) varied from some hours to one day, depending on temperature and loading of the material. Typically, one isotherm took 1 week to measure.

We studied four samples: chemically pure, commercial sodium chloride, calcium chloride, and magnesium chloride (purity $>99.99 \%$ ) and a halite sample from the Atacama Desert (purity 96-99\%), with few impurities of gypsum and silicates (Wierzchos et al., 2006). We chose these salts as likely candidates for the chloride-bearing deposits found on Mars based on geochemical measurements and chemical relationships (Clark and Van Hart, 1981). Furthermore, chlorides have been identified at all landing sites and from orbit (Clark and Baird, 1979; Osterloo et al., 2008; Hecht et al., 2009); and $\mathrm{Na}, \mathrm{Ca}$, and $\mathrm{Mg}$ are among the major cations found in the soil (Clark and Baird, 1979; Karunatillake et al., 2007; Hecht et al., 2009). This group of salts also covers a wide range of DRH and eutectic values (Table 1) and can therefore be used as representative chloride salts.

Before each water sorption experiment, approximately $150 \mathrm{mg}$ of each sample was degassed in the balance at $403 \mathrm{~K}$ (sodium chloride, Atacama halite) or at $533 \mathrm{~K}$ (calcium chloride, magnesium chloride) and pressure $<10^{-5} \mathrm{mbar}$ for several hours to minimize the starting amount of water in the samples. Under these conditions, sodium chloride and calcium chloride lose all water sorbed. The magnesium chloride sample, however, did not desorb all its hydration molecules, and we started the experiment with the sample in the dihydrate form $\left(\mathrm{MgCl}_{2}: 2 \mathrm{H}_{2} \mathrm{O}\right)$. It is important to mention that the dihydrate of magnesium chloride is rather stable and tends to decompose to form $\mathrm{HCl}$ at higher temperatures. Atacama halite and the commercial sodium chloride were measured as supplied, whereas calcium chloride and magnesium chloride were accommodated as small crystals (magnesium chloride about $300 \mathrm{~nm}$ ) in mesoporous silica by a standard impregnating procedure. This procedure makes the handling of the samples easier because calcium chloride, for instance, becomes liquid at higher humidity values. The silica support itself is hydrophobic (Jänchen et al., 2004) and does not influence the hydration/dehydration properties of the salts to a large extent. Thermogravimetric and differential scanning calorimetric measurements of the pure salts and the embedded materials do not show significant differences.

\subsection{Water activities of deliquescence solutions}

Terrestrial organisms appear to have sharp limits of biological activity with respect to temperature (Price and Sowers, 2004) and water activity $\left(a_{\mathrm{w}}\right)$ (Williams and Hallsworth, 2009) (see Discussion). For this reason, these two parameters have been used to define special regions on Mars and to establish planetary protection protocols. According to the Committee for Space Research (COSPAR) and NASA (COSPAR 2005; MEPAG, 2006), a special region on Mars is "a region within which terrestrial organisms are likely to propagate, or a region which is interpreted to have a high potential for the existence of extant martian life forms. Given current understanding, this applies to regions where liquid water is present or may occur." While $a_{\mathrm{w}}$ and temperature alone cannot be used to establish whether a given environment is habitable or not, both parameters taken together can be used, as a first approximation, to establish whether known terrestrial organisms would be able to survive in an environment where liquid water occurs.

The evolution of $a_{\mathrm{w}}$ in a binary system composed of water and salt is highly dependent on both the initial concentration of the solution and the induced supersaturation pathway, which, in turn, determines the sequence of phase precipitation. Numerical models are in part limited by the number of species and mineral phases included in the geochemical databases. The values provided by the model can be constrained, however, by the values of $a_{\mathrm{w}}$ that have been estimated empirically and the expected values of $a_{\mathrm{w}}$ of ice at low temperatures. For the ice-liquid equilibrium, the water vapor pressure above the solution is the same as above pure ice at the same temperature. In that case, the $a_{\mathrm{w}}$ of a given solution is a function of the temperature, and can be estimated from

$$
a_{\mathrm{w}}=p_{\mathrm{w}, \mathrm{s}} / p_{\mathrm{w}, 1}
$$

where $p_{\mathrm{w}, \mathrm{s}}$ is the water vapor pressure over ice, and $p_{\mathrm{w}, \mathrm{l}}$ is the water vapor pressure over pure liquid water (Koop et al., 2000).

We analyzed the evolution of $a_{\mathrm{w}}$ of solutions that result from mineral deliquescence of sodium chloride, calcium chloride, and magnesium chloride as a function of temperature by performing geochemical calculations. We investigated the evolution of $a_{\mathrm{w}}$ of saturated solutions of these salts at temperatures between $298 \mathrm{~K}$ and their respective eutectics. For simple concentrated solutions of highly soluble salts with starting high ionic strength, the Pitzer equations provide a more precise approximation to the evolution of $a_{\mathrm{w}}$ with temperature (i.e., Marion and Kargel, 2008). For that reason, in our model the activity coefficients and the activity of water were calculated with the Pitzer equations. The FREZCHEM (Marion and Kargel, 2008) and the PHREEQC codes, provided with the Pitzer database, were employed in the calculations. FREZCHEM is an equilibrium chemical thermodynamic model parameterized for concentrated electrolyte solutions (to ionic strengths $>20$ molality) for the temperature range from 200 to $298 \mathrm{~K}$ and the pressure range from 1 to 1000 bar (Marion and Kargel, 2008). PHREEQC is a computer program that is designed to perform a wide variety of low-temperature aqueous geochemical calculations (Charlton et al., 1997). We used both programs to test their consistency and validate the results.

For all three salts, the changes of $a_{\mathrm{w}}$ with temperature down to their eutectic temperature were measured starting at $298 \mathrm{~K}$. The case of magnesium chloride was more complex to model than sodium chloride or calcium chloride due to greater number of phases with different hydration states 


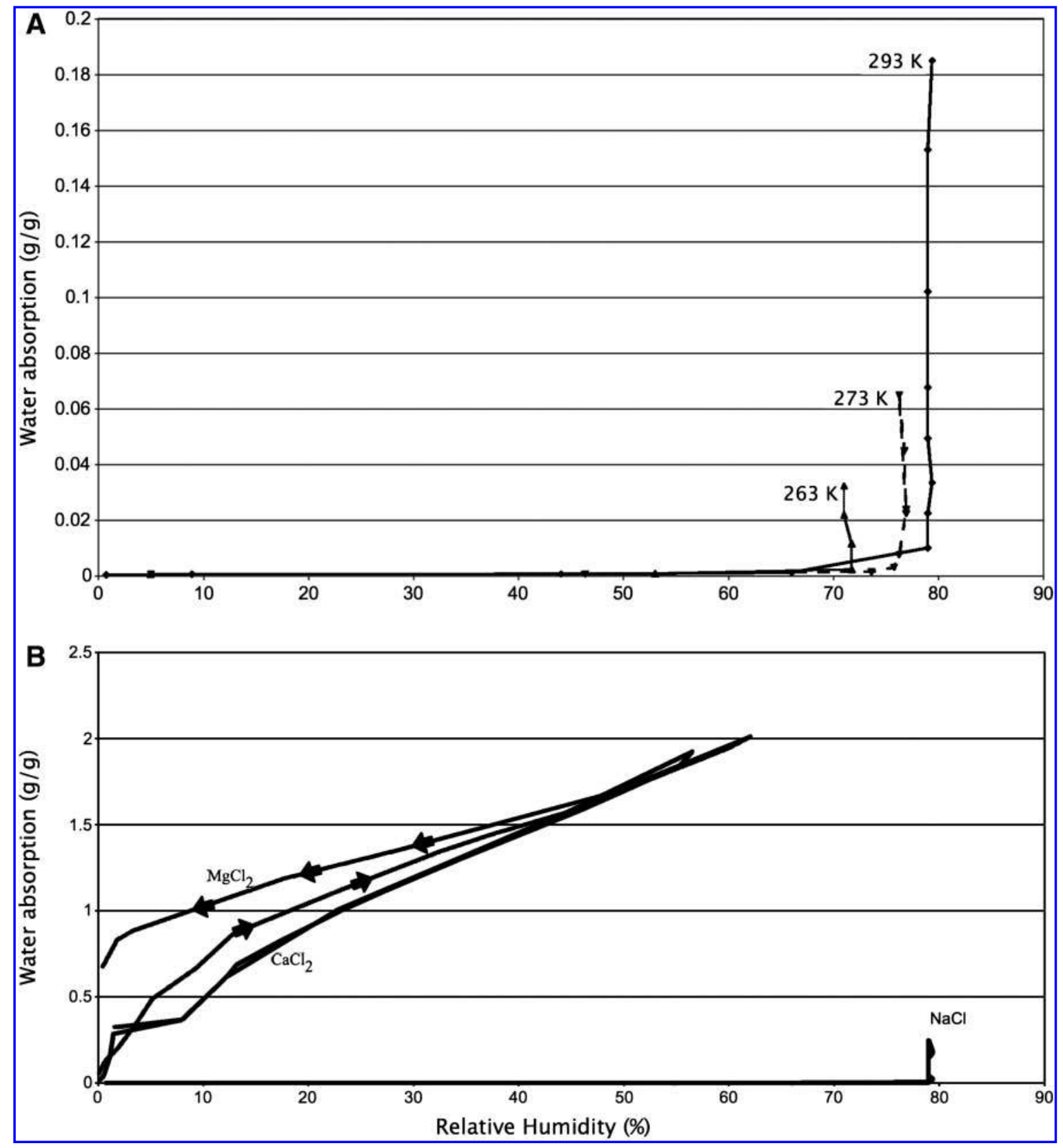

FIG. 3. (A) Hydration and dehydration isotherms of Atacama halite at $T=263,273$, and $293 \mathrm{~K}$. The water uptake in $\mathrm{g}$ water/g dry salt is plotted against the RH. At all temperatures, the water uptake rises at a RH close to the deliquescence RH of halite (ca. $75 \%$ ). (B) Comparison of the hydration and dehydration isotherms at $293 \mathrm{~K}$ for sodium chloride, calcium chloride, and magnesium chloride as a function of the relative humidity. For the case of magnesium chloride, arrows indicate increase or decrease of the relative humidity. Note the fast hydration of calcium chloride and magnesium chloride, whereas sodium chloride absorbs water only at the expected deliquescence point. See text for further details.

that can precipitate out during the cooling of the solution. The model results for each salt are highly dependent on several factors, such as the initial concentration and the sequence of phases that precipitate out of the solution; and the solubility dependence on temperature, for many of the hydrated species of magnesium chloride, has not yet been accurately determined. With such a limitation, we modeled a scenario in which the three stable phases for this range of temperatures could precipitate $\left(\mathrm{MgCl}_{2}: 6 \mathrm{H}_{2} \mathrm{O}, \mathrm{MgCl}_{2}: 8 \mathrm{H}_{2} \mathrm{O}\right.$, $\left.\mathrm{MgCl}_{2}: 12 \mathrm{H}_{2} \mathrm{O}\right)$.

\subsection{Mars relative humidity and temperature model}

We used the European Mars Climate Database (EMCD vs 4.3; Forget et al., 1999) to retrieve the annual fluctuations of atmospheric RH and T in the region shown on Figs. 1 and 2. A detailed description of the model and its working functions and parameters can be found in Lewis et al. (1999) and Forget et al. (1999). For the model runs, we used the Global Climate Model that has been tuned to fit the revised data provided by the Mars Global Surveyor Thermal Emission 
Spectrometer (TES) (Sprague et al., 2006), which is considered to be the actual reference for the water vapor variability in the martian atmosphere. Nevertheless, it is important to note that some discrepancies have been found between TES and data provided by the Mars Express mission, which uses three different instruments (OMEGA, Spicam, and PFS) and provides different values (from TES and even internally) that are significantly drier than TES. The reasons for these discrepancies are still being discussed (Fedorova et al., 2006; Fouchet et al., 2007; Melchiorri et al., 2007).

The EMCD is composed of different databases that allow for estimation of the parameters in different scenarios, including a cold or warm scenario or a dust storm scenario. For the present study, we selected a database that better describes the current conditions of the martian atmosphere in terms of the water vapor at ground level, the ground temperature, and the ground pressure. The spatial and temporal resolution of the model is $5.6^{\circ}$ for longitude, $3.6^{\circ}$ for latitude, 2 hours for local time and $30^{\circ}$ for solar longitude (Ls). Large annual cycles observed in many variables, such as $\mathrm{RH}$ and ground temperature, result in large databases that are difficult to manage. To reduce the mass storage requirements, the EMCD performs some temporal averages (Lewis et al., 1999). The model splits the martian year into 12 seasons of equal length in solar longitude ( $30^{\circ}$ each). Therefore a "day" in the model is taken to mean a martian solar day (about 88,775s), and an "hour" is taken to mean $1 / 24^{\text {th }}$ of a solar day. Within each season, the model stores mean values of each variable at 12 universal times in order to resolve the large martian diurnal cycles (Lewis et al., 1999).

The RH is not directly provided by the EMCD, but it is easily retrieved by combining the ground temperature/ pressure and water vapor mixing ratio near the ground. For the saturation pressure, the equations provided by Buck (1981) offer a better fit for the present martian conditions.

\section{Results}

\subsection{Water sorption/desorption isotherm measurements}

Figure $3 \mathrm{a}$ is a summary of the results of the isotherm measurements on a halite crust from the Atacama Desert for three different temperatures and as a function of the relative humidity. For all temperatures, the curves rise almost vertically between $70 \%$ and $80 \% \mathrm{RH}$, which indicates a sudden increase of mass. This occurs within the range of expected values of the DRH of sodium chloride, which has been estimated empirically at 75\% \pm 1 (Tang et al., 1977; Cohen et al., 1987). As can be seen in Fig. 3a, the amount of water absorbed by the sample decreased with decreasing temperature. At $293 \mathrm{~K}$, the halite crust absorbed an amount of water equivalent to $18 \%$ of its own weight, whereas at $263 \mathrm{~K}$ this value decreased to $6 \%$.

Figure $3 b$ shows a comparison of the isotherm measurements for the commercial chloride samples at $293 \mathrm{~K}$ as a function of relative humidity. As can be seen, the response of the salts to increasing humidity varied greatly. $\mathrm{CaCl}_{2}$ and $\mathrm{MgCl}_{2}$ readily hydrated at $\mathrm{RH}$ values $<10 \% . \mathrm{CaCl}_{2}$ was originally dehydrated and reached the hexahydrate form at around 30\%. Above 30\%, deliquescence is expected to occur (Greenspan, 1977; Cohen et al., 1987). From that point and up to a $\mathrm{RH}$ of $56 \%$, the calcium chloride sample absorbed an amount of water equivalent to approximately $60 \%$ of its own weight. Since the hexahydrate was the highest hydrated form at the temperatures of the experiment, we concluded that the extra water absorbed above 30\% formed a deliquescent solution. The behavior of $\mathrm{MgCl}_{2}$ was more complicated because it already contained $0.378 \mathrm{~g} / \mathrm{g} \mathrm{H}_{2} \mathrm{O}$ as dihydrate at the starting point of the isotherms $(0 \mathrm{~g} / \mathrm{g})$, so the formation of the hexahydrate (bischofite) occurred at about $\mathrm{RH}=11 \%$. On the other hand, $\mathrm{NaCl}$ did not absorb any $\mathrm{H}_{2} \mathrm{O}$ below the $\mathrm{RH}$ of $78 \%$.

As the $\mathrm{RH}$ decreased, the pure $\mathrm{NaCl}$ sample lost most of the absorbed water between $70 \%$ and $80 \%$ of the $\mathrm{RH}$, and the isotherms appear to be reversible. This result was unexpected, as previous studies have shown that the deliquescence/ efflorescence curve of halite crystals shows a characteristic hysteresis, with efflorescence occurring at 45-50\% (i.e., Biskos et al., 2006, and references therein). The isotherms of magnesium chloride are not reversible (especially for the hexahydrate part), and this might be due to kinetic effects of the dehydration process of the salt.

\subsection{Water activities of deliquescence solutions}

Figure 4a shows the variation of $a_{\mathrm{w}}$ as a function of temperature for a saturated solution of sodium chloride between $298 \mathrm{~K}$ and its eutectic $(253 \mathrm{~K})$. At $298 \mathrm{~K}$, the $a_{\mathrm{w}}$ of the solution is 0.75 , a value consistent with published data (Cohen et al., 1987; Tang and Munkelwitz, 1993). The $a_{\mathrm{w}}$ is practically constant between 298 and $265 \mathrm{~K}$, at which point it starts increasing abruptly, reaching 0.82 at the eutectic of the solution $(252 \mathrm{~K})$. The $a_{\mathrm{w}}$ of pure ice at the same temperature as calculated from Eq. 1 is 0.81 ; therefore our data are in very good agreement with empirical and theoretical values. The behavior of $a_{\mathrm{w}}$ with temperature is due to the stability of the dehydrated (halite- $\mathrm{NaCl}$ ) and hydrated (hydrohalite$\mathrm{NaCl}: 2 \mathrm{H}_{2} \mathrm{O}$ ) phases. At temperatures above $273 \mathrm{~K}$ the stable phase is halite, with a solubility that is practically independent of temperature. At temperatures below $273 \mathrm{~K}$ both halite and hydrohalite $\left(\mathrm{NaCl}: 2 \mathrm{H}_{2} \mathrm{O}\right)$ are stable, but the hydrated phase has a lower solubility and precipitates at temperatures below $265 \mathrm{~K}$. As a consequence, $\mathrm{Na}$ and $\mathrm{Cl}$ ions are removed from the solution, which results in a net decrease of the ionic strength and an increase of the $a_{\mathrm{w}}$. Below the eutectic, ice starts to form, and the $a_{\mathrm{w}}$ of the solution decreases accordingly.

Figure $4 \mathrm{~b}$ shows the variation of $a_{\mathrm{w}}$ with temperature for a saturated solution of calcium chloride between $298 \mathrm{~K}$ and its eutectic. The $a_{\mathrm{w}}$ of the saturated solution at $298 \mathrm{~K}$ is approximately 0.4 . Between 298 and $282 \mathrm{~K}$, the dihydrate phase is the most stable one; but, below $282 \mathrm{~K}$, antarcticite $\left(\mathrm{CaCl}_{2}: 6 \mathrm{H}_{2} \mathrm{O}\right)$ can also precipitate. Below this temperature, the evolution of $a_{\mathrm{w}}$ is a result of three competing processes. On one hand, the precipitation of $\mathrm{Ca}^{2+}$ and $\mathrm{Cl}^{-}$ions will tend to increase $a_{\mathrm{w}}$. On the other hand, the precipitation of a hydrated phase (antarcticite) removes water molecules from the solution and will tend to decrease $a_{\mathrm{w}}$. In the same way, the formation of ice also contributes to decreasing $a_{\mathrm{w}}$. The removal of $\mathrm{Ca}^{2+}$ and $\mathrm{Cl}^{-}$ions from the solution as the temperature is lowered is more efficient than the removal of water molecules, and this results in a net increase in the $a_{\mathrm{w}}$ of the solution toward lower temperatures until the eutectic is reached $(224 \mathrm{~K})$, where the maximum $a_{\mathrm{w}}$ is obtained $(0.62)$. 

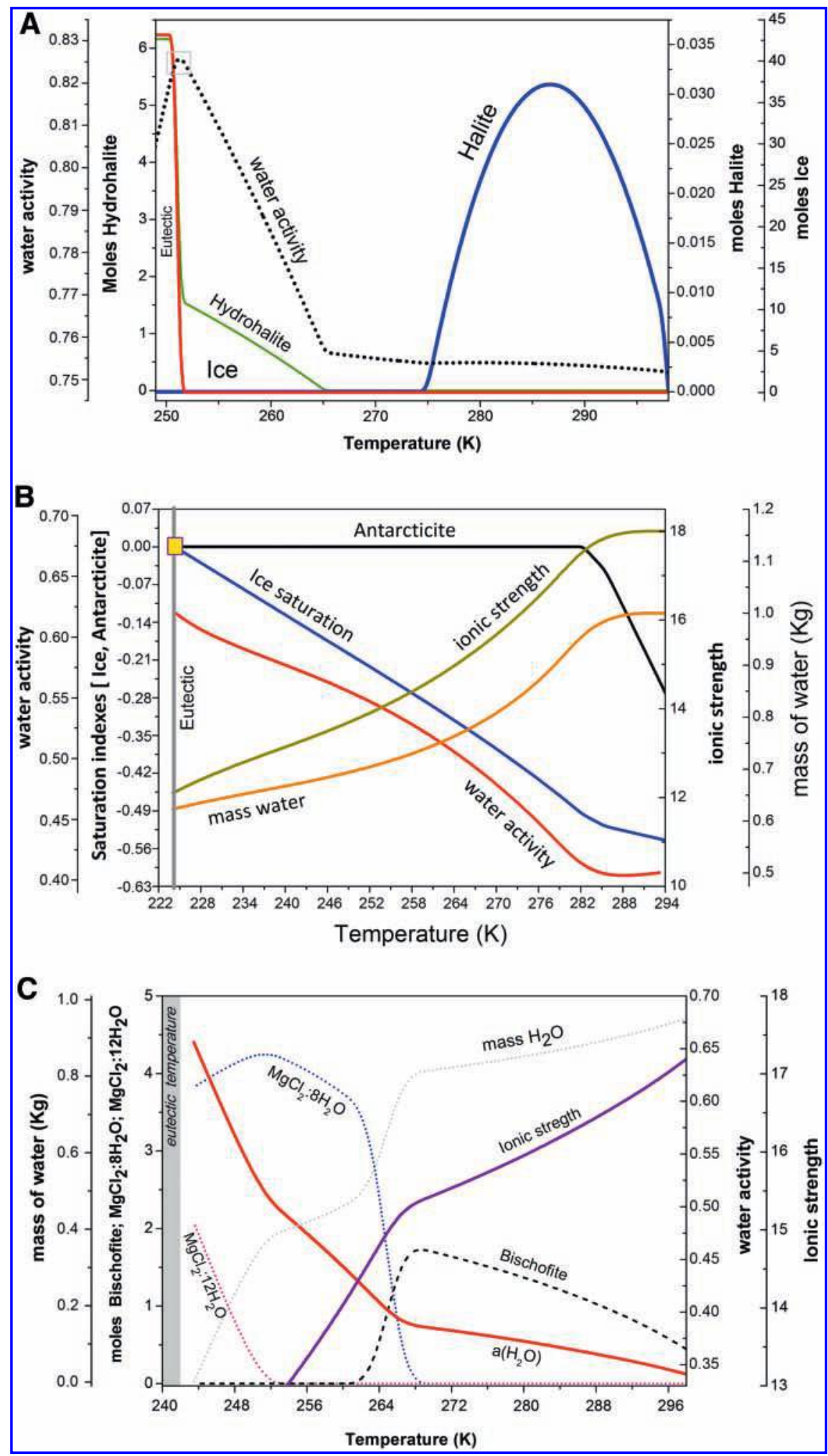

FIG. 4. Evolution of $a_{\mathrm{w}}$ of saturated solutions of three chloride salts as a function of temperature. (A) In the case of sodium chloride, as the temperature decreases the solubility of halite also decreases and precipitates, first as halite and later as hydrohalite. As a result of the precipitation of hydrohalite, the $a_{\mathrm{w}}$ increases at a faster rate until the eutectic point of the solution is reached at $252 \mathrm{~K}$. (B) In the case of calcium chloride, $a_{\mathrm{w}}$ increases steadily between $280 \mathrm{~K}$ and the eutectic ( $223 \mathrm{~K}$ ), due to the precipitation of antarcticite (6-hydrate), which removes ions from the system at a faster rate than water molecules, thereby decreasing the ionic strength of the solution. (C) Similarly, in the case of magnesium chloride, $a_{\mathrm{w}}$ increases as the temperature is lowered, particularly after the precipitation of the 8-hydrate $(266 \mathrm{~K})$ and the 12 -hydrate $(250 \mathrm{~K})$. Color images available online at www.liebertonline.com/ast. 
The $a_{\mathrm{w}}$ of pure ice at the same temperature as calculated from Eq. 1 is 0.61 ; therefore our model is also in very good agreement with empirical and theoretical values.

Figure 4c shows the variation of $a_{\mathrm{w}}$ with temperature for a saturated solution of magnesium chloride between $298 \mathrm{~K}$ and its eutectic. The initial saturated solution has an $a_{\mathrm{w}}$ of 0.34 at $298 \mathrm{~K}$, a value consistent with experimental results (Greenspan, 1977). As occurs with the other salts, the evolution of $a_{\mathrm{w}}$ depends on the balance between processes that decrease the ionic strength of the solution (removal of $\mathrm{Mg}^{2+}$ and $\mathrm{Cl}^{-}$ions) and those that increase the ionic strength (removal of water molecules). The $a_{\mathrm{w}}$ of the saturated solution increases at lower temperatures because the removal of salt ions is more efficient than the removal of water molecules. Due to the sequential precipitation of phases with increasing hydration states [first bischofite $\left(\mathrm{MgCl}_{2}: 6 \mathrm{H}_{2} \mathrm{O}\right)$, then $\mathrm{MgCl}_{2}: 8 \mathrm{H}_{2} \mathrm{O}$ at $268 \mathrm{~K}$, and finally $\mathrm{MgCl}_{2}: 12 \mathrm{H}_{2} \mathrm{O}$ at $255 \mathrm{~K}$ ], the water in the system is practically consumed near the eutectic point, and the model run stops just before the eutectic temperature, when ice precipitation starts. The $a_{\mathrm{w}}$ of the remaining solution determined at this point is 0.656 .

\subsection{Mars relative humidity $(R H)$ and temperature $(\mathrm{T})$ model}

We modeled the $\mathrm{RH}$ and $T$ variations in a martian region (Figs. 1 and 2) where putative evaporitic chloride deposits were identified by Osterloo et al. (2008). Figure 5 shows the fluctuations of $\mathrm{RH}$ and ground temperature throughout one martian year, measured as Ls from $0^{\circ}$ to $360^{\circ}$ and averaged for each season (see Lewis et al., 1999) in that region. As expected, averaged $\mathrm{RH}$ and ground temperature are anticorrelated, with peaks in the RH coincident with the minimum ground temperatures. For most of the martian year, $\mathrm{RH}$ reaches $100 \%$ every season. Between Ls $0^{\circ}$ and $200^{\circ}$, the averaged minimum $\mathrm{RH}$ is higher than during the rest of the year, with peak values of $60 \%$. Between Ls $200^{\circ}$ and $360^{\circ}$, the maximum RH occasionally does not reach $100 \%$, and it falls to $0 \%$ every day. The ground temperature reaches values above $270 \mathrm{~K}$ between Ls $200^{\circ}$ and $360^{\circ}$. The maximum ground temperature during this period is $305 \mathrm{~K}$, and the minimum is $165 \mathrm{~K}$. Average daily oscillations are on the order of 110$120 \mathrm{~K}$. The region witnesses the lowest ground temperatures (daily maxima between 230 and $270 \mathrm{~K}$; daily minima between 160 and $170 \mathrm{~K})$ during local fall and winter (Ls $0^{\circ}$ to $200^{\circ}$ ). Therefore, average RH values often fall above the deliquescence points of all three salts considered here (Table 1).

\section{Discussion}

\subsection{Deliquescence of chloride salts on Mars}

The present climate conditions on Mars (mainly the low atmospheric pressure and the low temperatures) are such that they prevent the occurrence of liquid water at large scales on the surface (Haberle et al., 2001). However, locally, mineral deliquescence can be a potential source of transient brine solutions with a depressed freezing point (Rennó et al., 2009). For example, perchlorate deliquescence has been proposed as a mechanism to explain the formation of transient brine solu-

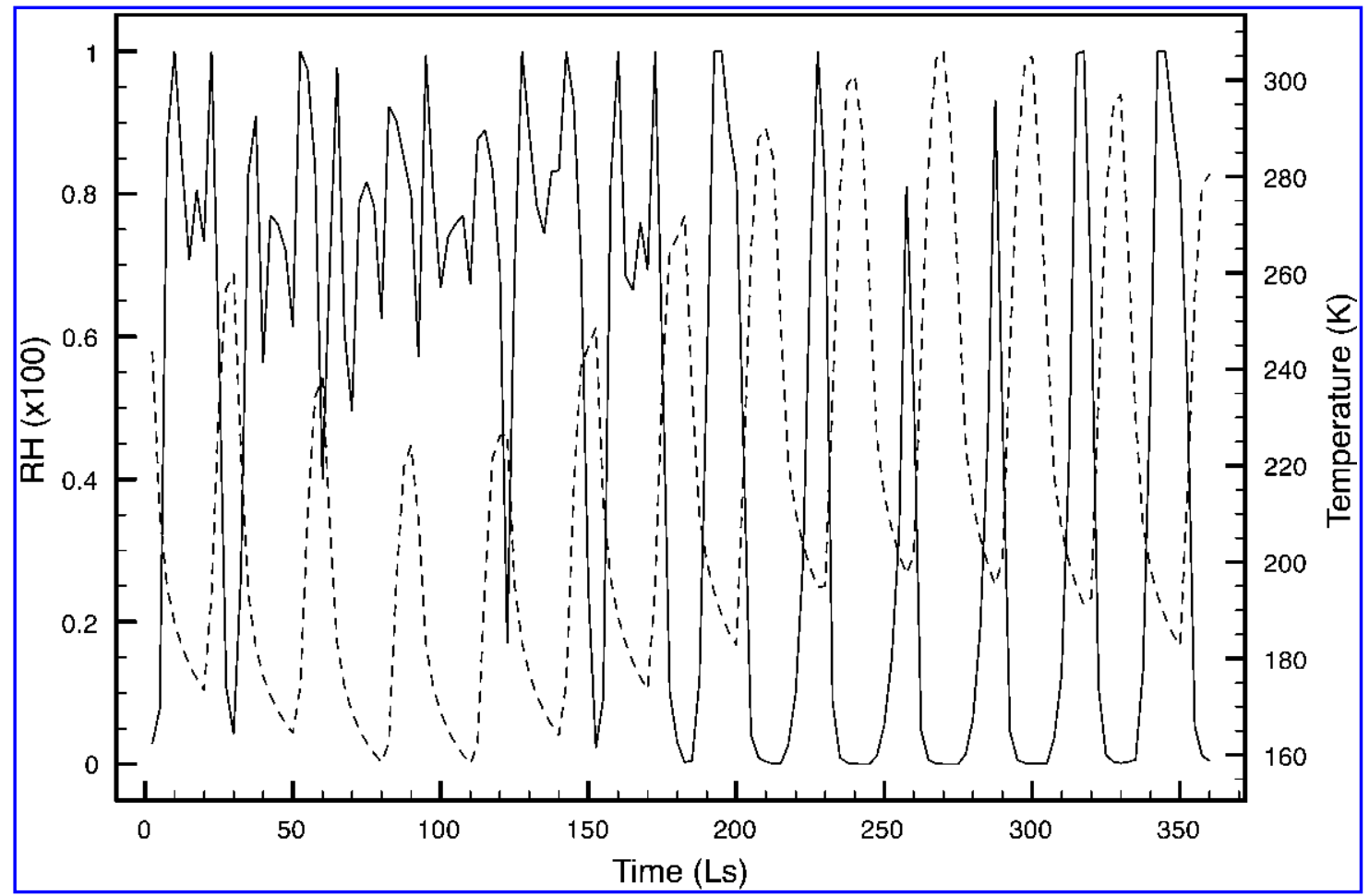

FIG. 5. Annual relative humidity (solid line) and ground temperature (dashed line) fluctuations in the region shown in Fig. 2. Ls is the solar longitude, where $360^{\circ}=1$ year. Between Ls $=0$ and Ls $=200$, the relative humidity is higher and often reaches saturation. However, the temperatures are very low, with maxima around $250 \mathrm{~K}$. Between Ls $=200$ and Ls $=360$, the temperatures increase, often above $273 \mathrm{~K}$, whereas the RH drops, although it still often reaches the deliquescence point of sodium chloride, calcium chloride, and magnesium chloride (Table 1). 
tions in soils at the Phoenix landing site (Chevrier et al., 2009; Rennó et al., 2009; Zorzano et al., 2009) and elsewhere where similar hygroscopic minerals exist on the surface. Aside from perchlorate, other chloride salts such as sodium chloride, calcium chloride, and magnesium chloride are also hygroscopic (Table 1, Fig. 3). The ions of these salts have been identified in soils at all landing sites as major elements, at concentrations up to $0.5-5 \%$ (i.e., Karunatillake et al., 2007), and are thought to be globally distributed on the surface (Clark, 1978; Clark and Van Hart, 1981). Putative chloride-bearing deposits in the southern highlands appear to have an evaporitic origin (Osterloo et al., 2008; Fig. 2), which suggests that the concentration of salts in these deposits might be much higher than in the soils and similar to salt flats found in the drier parts of the Atacama Desert (Lowenstein et al., 2003). If the salts that form these deposits are hygroscopic, then deliquescence is expected to occur if the environmental conditions allow it.

The climate model presented in this work indicates that the DRH of sodium chloride, calcium chloride, and magnesium chloride $(75 \%, 30 \%$, and $33 \%$, respectively) are reached often for a significant portion of the martian year in the region shown in Figs. 1 and 2. At this point, the salt crusts would deliquesce and spontaneously form a saturated solution. The model also predicts peak daily ground temperatures above the eutectic of the three salts for almost half a martian year. Maximum RH occur when the temperatures are lower and drop fast as the ground temperature increases. Given the resolution of the model, it is not possible to predict whether episodes of deliquescence will overlap with temperatures above the eutectic at the hourly or daily basis, at which point a liquid brine would be stable. Another limitation to the formation of a brine solution is the amount of water vapor available in the atmosphere. The present-day martian atmosphere is extremely dry, with typical amounts of water vapor between 1 and 100 precipitable micrometers (Fouchet et al., 2007). This is approximately $2-3$ orders of magnitude drier than the driest parts of the Atacama Desert (Lane, 1998). Rivkina et al. (2000) showed that active life processes are effective at water contents down to only two monolayers, and theoretical and experimental results point to the existence of nanometer-sized thin films of undercooled liquid interfacial water associated with the surfaces of micrometer-sized, and larger, mineral particles in icy environments far below the melting point temperature, which could be enough to sustain biological processes (Möhlmann, 2008). While these studies indicate that very little liquid water might suffice to allow for microbial activity, the number of unknown parameters likely to play a role in the stability and abundance of brines in hygroscopic minerals (i.e., porosity, density, composition), prevents us from establishing unambiguously whether deliquescent solutions of sodium chloride, calcium chloride, or magnesium chloride will form on present-day Mars and, if so, how much liquid water will form.

Mineral deliquescence might have been more important during periods of high obliquity, when increasing polar summer insolation enhances the polar ice sublimation and results in a globally higher content of water vapor in the atmosphere, with water column abundance up to 3000 precipitable micrometers above the northern polar cap during summer solstice (Forget et al., 2006). In this scenario, theoretical models predict water ice accumulation reaching 30 $70 \mathrm{~mm}$ per year in several localized areas near the equator
(Forget et al., 2006). These episodes of high obliquity have been common throughout the most recent geological period of Mars (the Amazonian, 1.8 Gyr to present) and last occurred as recently as $5 \times 10^{6}$ years ago (Laskar et al., 2002). Episodes of mineral deliquescence would have been more common and intense during these periods and further back in time when the conditions on the surface of Mars were even wetter (i.e., Carr, 1996). Therefore, with the available data, we cannot establish unambiguously that deliquescent brines form under current conditions in deposits such as the one shown in Fig. 2, but the probability for this to happen increases as we move back in time.

\subsection{Habitability of chloride deposits on Mars}

The potential for biological activity in a given environment can be established based on two parameters: temperature and water activity $\left(a_{\mathrm{w}}\right)$ (Price and Sowers, 2004; MEPAG, 2006; Williams and Hallsworth, 2009). Based on their own model results and published data, Price and Sowers (2004) suggested three levels of metabolic state of microorganisms: (i) active growth, (ii) maintenance without growth, and (iii) survival metabolism. Currently, no direct observation of cell replication has been shown below $253 \mathrm{~K}$ (Rivkina et al., 2000), and Price and Sowers (2004) found no evidence of a threshold in survival metabolic rates down to $233 \mathrm{~K}$. Maintenance metabolism (access to nutrients and freedom of movement but without growth) has been reported at temperatures down to $253 \mathrm{~K}$, which is coincident with the minimum growth temperatures; but it is expected that the actual limit lies between 253 and $233 \mathrm{~K}$ (Price and Sowers, 2004).

On the other hand, $a_{\mathrm{w}}$ is a measure of the water availability in a given environment. While the $a_{\mathrm{w}}$ of pure water is always 1 , that of an aqueous solution is always $<1$. Most terrestrial organisms are adapted to environments where $a_{\mathrm{w}}>0.95$. Halophilic and halotolerant bacteria grow in environments with $a_{\mathrm{w}}$ between 0.75 and 0.80 , and up to this day some osmophilic yeasts and a few molds have been shown to be capable of growth at water activity $a_{\mathrm{w}}$ between 0.61 and 0.65 . Below 0.61 , no microbial proliferation has been shown (Harris, 1961; Tapia et al., 2007).

For the salts studied here, the geochemical model of the evolution of $a_{\mathrm{w}}$ of deliquescent solutions shows that $a_{\mathrm{w}}$ increases with decreasing temperature as a result of salt precipitation and the subsequent removal of dissolved species. This is a relevant and counterintuitive result, and it shows that a given aqueous environment will become more habitable in terms of $a_{\mathrm{w}}$ as the temperature is lowered. Using the temperature and $a_{\mathrm{w}}$ limits stated above for terrestrial microorganisms, we plotted the expected metabolic state of organisms living inside deposits of deliquescent salts (sodium chloride, calcium chloride, and magnesium chloride) as a function of $a_{\mathrm{w}}$ and temperature (Fig. 6). In the plot, we highlighted the current $a_{\mathrm{w}}$ limit of terrestrial microorganisms (solid black line) and the limit of $a_{\mathrm{w}}$ used to define special regions on Mars ( $a_{\mathrm{w}}=0.5$, dashed black line). As can be seen, the deliquescence solution of sodium chloride would allow for the growth of terrestrial microorganisms at all temperatures, down to the eutectic, while the deliquescence solution of calcium chloride would not be compatible with growth or metabolic activity at any temperature. Deliquescence solutions of magnesium chloride would only be compatible with 


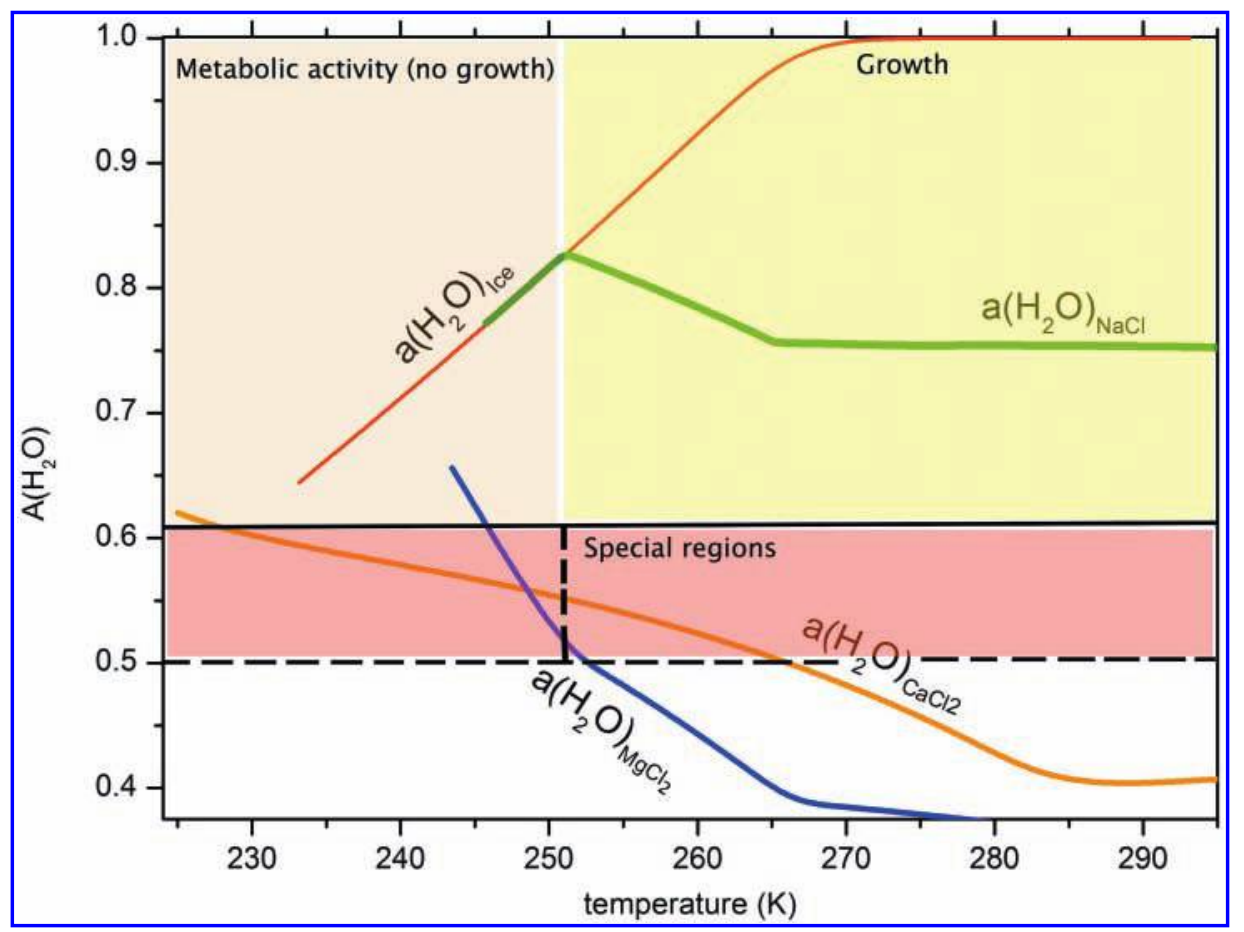

FIG. 6. Expected metabolic state of organisms living inside deposits of deliquescent salts as a function of $a_{\mathrm{w}}$ and temperature, based on estimated limits of terrestrial organisms (Harris, 1961; Price and Sowers, 2004; Tapia et al., 2007). The green square represents the region of the plot where microbial growth is possible. The orange region represents the region of the plot where only microbial metabolism is possible. The red square represents the region of the plot that defines special regions on Mars (MEPAG, 2006). The solid black line corresponds to $a_{\mathrm{w}}=0.61$. The dashed black lines correspond to $a_{\mathrm{w}}=0.5$ (horizontal) and $T=253 \mathrm{~K}$ (vertical) and are the lower limits for the propagation of organisms used to define special regions on Mars. Color images available online at www.liebertonline.com/ast.

metabolic activity at temperatures close to the eutectic (245$240 \mathrm{~K})$. On the other hand, taking the $a_{\mathrm{w}}$ limit used to define special regions on Mars (dashed dark line), the deliquescence solution of calcium chloride would fall within the region in the plot where growth is possible, at temperatures between 265 and $253 \mathrm{~K}$, and within the region where metabolism is still possible (but no growth), at temperatures between 253 and $233 \mathrm{~K}$. Taking the same limit, magnesium chloride would allow only for metabolism between $253 \mathrm{~K}$ and its eutectic. These results show that salts can play a key role in the habitability of extremely dry environments.

The observation that $a_{\mathrm{w}}$ of deliquescent solutions of sodium chloride, calcium chloride, and magnesium chloride increases as the temperature lowers implies that these types of deposits have a strong astrobiological potential in cold and dry environments, both on Earth and on Mars. In the Atacama Desert, the driest region on Earth, photosynthetic microorganisms have migrated from the soil and into sodium chloride crusts (Wierzchos et al., 2006), taking advantage of the hygroscopic properties of this salt (Davila et al., 2008). On Mars, with much drier conditions than the Atacama, a similar strategy appears plausible, particularly in earlier times when the abundance of water vapor in the martian atmosphere was likely higher and deliquescence processes must have been more common and intense. Our results can be used to constrain the habitability of the martian surface, as well as cold environments on Earth, such as the saturated $\mathrm{CaCl}_{2}$ brine of Don Juan pond in Antarctica, and the putative cold oceans under the ice shells of Europa and Enceladus.

\section{Conclusions}

Following the results presented here, we conclude the following:

(1) Geomorphological and spectroscopic evidence indicates the presence of chloride-bearing deposits formed in an evaporitic environment on Mars (Osterloo et al., 2008; Figs. 1 and 2). These deposits are similar to salt flats in the Atacama Desert, which are a habitat for photosynthetic and heterotrophic bacteria (Wierzchos et al., 2006).

(2) Modeled climate data show that the average RH in one of the regions with chloride-bearing deposits (Fig. 2) often reaches values above the DRH of sodium chloride, calcium chloride, and magnesium chloride, while ground temperature often reaches values above the eutectic of the three salts. The model cannot resolve $\mathrm{RH}$ and temperature conditions at an hourly or daily basis.

(3) A lack of detailed data about the physical and chemical properties of the chloride-bearing deposits prevents us from estimating the actual amount of deliquescent brine that could form in these deposits, if any.

(4) The water activity of deliquescent solutions of sodium chloride, calcium chloride, and magnesium chloride increases with decreasing temperature, down to their respective eutectics.

(5) The deliquescence of sodium chloride deposits on present-day Mars would result in a solution with $a_{\mathrm{w}}$ 
compatible with the growth of terrestrial microorganisms down to a temperature of $252 \mathrm{~K}$ (eutectic).

(6) The deliquescence of calcium chloride and magnesium chloride deposits on present-day Mars would result in deliquescent solutions with $a_{\mathrm{w}}$ incompatible with the growth of terrestrial microorganisms, and magnesium chloride would be compatible with metabolic activity only at temperatures close to the eutectic.

(7) Given the limits of $a_{\mathrm{w}}$ used to define special regions on Mars (COSPAR, 2005; MEPAG, 2006), the deliquescence of calcium chloride deposits would allow for the growth of terrestrial microorganisms at temperatures between 265 and $253 \mathrm{~K}$, and for metabolic activity (no growth) at temperatures between 253 and $233 \mathrm{~K}$. Given the same limit, the deliquescence of magnesium chloride would allow only for microbial metabolism at temperatures close to the eutectic.

\section{Acknowledgments}

This work was supported by grants CGL2006-04658/BOS and CGL2007-62875/BOS from the Spanish Ministry of Science and Innovation and grant PIE-631A from the CSIC (Spanish Research Council), and by the Helmholtz Association through the research alliance "Planetary Evolution and Life." We greatly appreciate the comments and suggestions of Dennis Powers and an anonymous reviewer, which greatly improved the original manuscript.

\section{Abbreviations}

COSPAR, Committee for Space Research; DRH, deliquescence relative humidity; EMCD, European Mars Climate Database; Ls, solar longitude; RH, relative humidity; TES, Thermal Emission Spectrometer.

\section{References}

Bibring, J.P., Langevin, Y., Mustard, J., Poulet, P., Arvidson, R., Gendrin, A., Gondet, B., Mangold, N., Pinet, P., Forget, F., and the OMEGA Team (2006). Global mineralogical and aqueous Mars history derived from OMEGA/Mars Express data. Science 312:400-404.

Biskos, G., Malinowski, A., Russell, L.M., Buseck, P.R., and Martin, S.T. (2006) Nanosize effect on the deliquescence and the efflorescence of NaCl particles. Aerosol. Sci. Technol. 40:97-106.

Bobst, A.L., Lowenstein, T.K., Jordan, T.E., Godfrey, L.V., Ku, T.L., and Luo, S. (2001) A 106 ka paleoclimate record from drill core of the Salar de Atacama, northern Chile. Palaeogeogr., Palaeoclimatol., Palaeoecol. 173:21-42.

Buck, A.L. (1981) New equations for computing vapour pressure and enhancement factor. Iournal of Applied Meteorology 20: 1527-1532.

Carr, M.H. (1996) Water on Mars, Oxford University, New York. Charlton, S.R., Macklin, C.L., and Parkhurst, D.L. (1997) PHREEQCI-a graphical user interface for the geochemical computer program PHREEQC, Water Resources Investigations Report 97-4222, U.S. Geological Survey, Reston, Virginia.

Chevrier, V.F., Hanley, J., and Altheide, T.S. (2009) Stability of perchlorate hydrates and their liquid solutions at the Phoenix landing site, Mars. Geophys. Res. Lett. 36, doi:10.1029/2009 GL037497.

Clark, B.C. (1978) Implications of abundant hygroscopic minerals in the martian regolith. Icarus 34:645-665.
Clark, B.C. and Baird, A.K. (1979) Volatiles in the martian regolith. Geophys. Res. Lett. 6:811-814.

Clark, B.C. and Van Hart, D.C. (1981) The salts of Mars. Icarus 45:370-378.

Clarke, J.D.A. (2006) Antiquity of aridity in the Chilean Atacama Desert. Geomorphology 73:101-114.

Cohen, M.D., Flagan R.C., and Seinfel, J.H. (1987) Studies of concentrated electrolyte solutions using the electrodynamic balance, 1, water activities for single-electrolyte solutions. J. Phys. Chem. 91:4563-4574.

Connon, S.A., Lester, E.D., Shafaat, H.S., Obenhuber, D.C., and Ponce, A. (2007) Bacterial diversity in hyperarid Atacama Desert soils. J. Geophys. Res. 112, doi:10.1029/2006JG000311.

COSPAR. (2005) COSPAR Planetary Protection Policy (20 October 2002; amended 24 March 2005), COSPAR, Paris. Available online at http://cosparhq.cnes.fr/Scistr/Pppolicy.htm.

Davila, A.F., Gomez-Silva, B., de los Rios, A., Ascaso, C., Olivares, H., McKay, C.P., and Wierzchos, J. (2008) Facilitation of endolithic microbial survival in the hyperarid core of the Atacama Desert by mineral deliquescence. J. Geophys. Res. 113, doi:10.1029/2007JG000561.

Ericksen, G.E. (1983) The Chilean nitrate deposits. Am. Sci. 71: 366-374.

Fairén, A.G., Fernández-Remolar, D., Dohm, J.M., Baker, V.R., and Amils, R. (2004) Inhibition of carbonate synthesis in acidic oceans on early Mars. Nature 431:423-426.

Fairén, A.G., Davila, A.F., Gago-Duport, L., Amils, R., and McKay, C.P. (2009) Stability against freezing of aqueous solutions on early Mars. Nature 459:401-404.

Fedorova, E., Korablev, O., Bertaux, J.L., Rodin, A., Kiselev, A., and Perrier, S. (2006) Mars water vapor abundance from SPICAM IR spectrometer: seasonal and geographic distributions. J. Geophys. Res. 111, doi:10.1029/2006JE002695.

Forget, F., Hourdin, F., Fournier, R., Hourdin, C., Talagrand, O., Collins, M., Lewis, S.R., Read, P.L., and Huot, J. (1999) Improved general circulation models of the martian atmosphere from the surface to above $80 \mathrm{~km}$. I. Geophys. Res. 104:24155-24176.

Forget, F., Haberle, R.M., Montmessin, F., Levrard, B., and Head, J.W. (2006) Formation of glaciers on Mars by atmospheric precipitation at high obliquity. Science 311, doi:10.1126/ science. 1120335 .

Fouchet, T., Lellouch, E., Ignatiev, N., Forget, F., Titov, D.V., Tschimmel, M., Montemessin, F., Formisano, V., Giuranna, M., Maturilli, A., and Encrenaz, T. (2007) Martian water vapor: Mars Express PFS/LW observations. Icarus 190:32-49.

Greenspan, L. (1977) Humidity fixed points of binary saturated aqueous solutions. J. Res. Natl. Bur. Stand. 81A:89-96.

Haberle, R.M., McKay, C.P., Schaeffer, J., Cabrol, N.A., Grin, E.A., Zent, A.P., and Quinn, R. (2001) On the possibility of liquid water on present-day Mars. J. Geophys. Res. 106:2331723326.

Harris, R.F. (1961) The effect of water potential on microbial growth and activity. In Water Potential Relations in Soil Microbiology, edited by J.F. Parr, W.R. Gardner, and L.F. Elliot, Soil Science Society of America, Madison, WI, pp 23-95.

Hartley, A.J., Chong, G., Houston, J., and Mather, A.E. (2005) 150 million years of climatic stability: evidence from the Atacama Desert, northern Chile. I. Geol. Soc. London 162:421-424.

Hecht, M.H., Kounaves, S.P., Quinn, R.C., West, S.J., Young, S.M.M., Ming, D.W., Catling, D.C., Clark, B.C., Boynton, W.V., Hoffman, J., DeFlores, L.P., Gospodinova, K., Kapit, J., and Smith, P.H. (2009) Detection of perchlorate and the soluble chemistry of martian soil at the Phoenix lander site. Science 325:64-67. 
Jänchen, J., Ackermann, D., Stach, H., and Brösicke, W. (2004) Studies of the water adsorption on zeolites and modified mesoporous materials for seasonal storage of solar heat. $\underline{\text { Solar }}$ Energy 76:339-344.

Karunatillake, S., Keller, J.M., Squyres, S.W., Boynton, W.V., Brückner, J., Janes, O., Gasnault, D.M., and Newsom, H.E. (2007) Chemical compositions at Mars landing sites subject to Mars Odyssey Gamma Ray Spectrometer constraints. J. Geophys. Res. 112, doi:10.1029/2006JE002859.

Koop, T., Luo, B., Tsias, A., and Peter, T. (2000) Water activity as the determinant for homogeneous ice nucleation in aqueous solutions. Nature 406:611-614.

Lane, A.P. (1998) Submillimeter transmission at South Pole. In Astrophysics from Antarctica, ASP Conference Series Vol. 141, edited by R. Landsberg and G. Novak, Astronomical Society of the Pacific, San Francisco, pp 289-295.

Laskar, J., Levrard, B., and Mustard, J.F. (2002) Orbital forcing of the martian polar layered deposits. Nature 419:375-377.

Lewis, S.R., Collins, M., Read, P.L., Forget, F., Hourdin, F., Fournier, R., Hourdin, C., Talagrand, O., and Huot, J.-P. (1999) A climate database for Mars. I. Geophys. Res. 104:24177-24194.

Lowenstein, T.K., Hein, M.C., Bobst, A.L., Jordan, T.E., Ku, T.L., and Luo, S. (2003) An assessment of stratigraphic completeness in climate-sensitive closed-basin lake sediments: Salar de Atacama, Chile. Journal of Sedimentary Research 73:91-104.

Marion, G.M. and Kargel, J.S. (2008) Cold Aqueous Planetary Geochemistry with FREZCHEM: From Modeling to the Search for Life at the Limits, Advances in Astrobiology and Biogeophysics Series, Springer-Verlag, Berlin Heidelberg.

McKay, C.P., Friedmann, E.I., Gomez-Silva, B., CaceresVillanueva, L., Andersen, D., and Landheim, R. (2003) Temperature and moisture conditions for life in the extreme arid region of the Atacama Desert: four years of observations including the El Niño of 1997-1998. Astrobiology 3:393-406.

Melchiorri, R., Encrenaz, T., Fouchet, T., Drossart, P., Lellouch, E., Gondet, B., Bibring, J.-P., Langevin, Y., Schmitt, B., Titov, D., and Ignatiev, N. (2007) Water vapor mapping on Mars using OMEGA/Mars Express. Planet. Space Sci. 55:333-342.

MEPAG. (2006) Finding of the Mars Special Regions Science Analysis Group. Astrobiology 6:677-732.

Möhlmann, D.T. (2008) Are nanometric films of liquid undercooled interfacial water bio-relevant? Cryobiology 58:256-261.

Möhlmann, D.T. (2010) The three types of liquid water on the surface of present Mars. Int. J. Astrobiology 9:45-49.

Mustard, J.F., Murchie, S.L., Pelkey, S.M., Ehlmann, B.L., Milliken, R.E., Grant, J.A., Bibring, J.-P., Poulet, F., Bishop, J., Noe Dobrea, E.Z., Roach, L., Seelos, F., Arvidson, R.E., Wiseman, S., Green, R., Hash, C., Humm, D., Malaret, E., McGovern, J.A., Seelos, K., Clancy, T., Clark, R., Des Marais, D., Izenberg, N., Knudson, A., Langevin, Y., Martin, T., McGuire, P., Morris, R., Robinson, M., Roush, T., Smith, M., Swayze, G., Taylor, H., Titus, T., and Wolff, M. (2008) Hydrated silicate minerals on Mars observed by the Mars Reconnaissance Orbiter CRISM instrument. Nature 454:305-309.

Navarro-González, R., Rainey, F.A., Molina, P., Bagaley, D.R., Hollen, B.J., de la Rosa, J., Small, A.M., Quinn, R.C., Grunthaner, F.J., Cáceres, L., Gomez-Silva, B., and McKay, C.P. (2003) Mars-like soils in the Atacama Desert, Chile, and the dry limit of microbial life. Science 302:1018-1021.

Osterloo, M.M., Hamilton, V.E., Bandfield, J.L., Glotch, J.L., Baldridge, A.M., Christensen, P.R., Tornabene, L.L., and Anderson, F.S. (2008) Chloride-bearing meterials in the southern highlands of Mars. Science 319:1651-1654.
Price, P.B. and Sowers, T. (2004) Temperature dependence of metabolic activity rates for microbial growth, maintenance, and survival. Proc. Natl. Acad. Sci. U.S.A. 101:4631-4636.

Rennó, N.O., Bos, B.J., Catling, D., Clark, B.C., Drube, L., Fisher, D., Goetz, W., Hviid, S.F., Keller, H., Kok, J.F., Kounaves, S.P., Leer, K., Lemmon, M., Bo Madsen, M., Markiewicz, W., Marshall, J., McKay, C., Mehta, M., Smith, M., Zorzano, M.P., Smith, P.H., Stoker, C., and Young, S.M.M. (2009) Possible physical and thermodynamical evidence for liquid water on the Phoenix landing site. J. Geophys. Res. 114, doi:10.1029/2009JE003362.

Rivkina, E.M., Friedmann, E.I., McKay, C.P., and Gilichinsky, D.A. (2000) Metabolic activity of permafrost bacteria below the freezing point. Appl. Environ. Microbiol. 66:3230-3233.

Sprague, A.L., Hunten, D.M., Doose, L.R., Hill, R.E., Boynton, W.V., Smith, M.D., and Pearl, J.C. (2006) Mars atmospheric water vapor abundance: 1991-1999, emphasis 1998-1999. Icarus 184:372-400.

Squyres, S.W., Grotzinger, J.P., Arvidson, R.E., Bell, J.F., Calvin, W., Christensen, P.R., Clark, B.C., Crisp, J.A., Farrand, W.H., Herkenhoff, K.E., Johnson, J.R., Klingelhöfer, G., Knoll, A.H., McLennan, S.M., McSween, H.Y., Morris, R.V., Rice, J.W., Rieder, R., and Soderblom, L.A. (2004) In situ evidence for an ancient aqueous environment at Meridiani Planum, Mars. Science 306:1709-1714.

Tang, I.N. and Munkelwitz, H. (1993) Composition and temperature dependence of the deliquescence properties of hygroscopic aerosols. Atmos. Environ. 274:467-473.

Tang, I.N., Munkelwitz, H.R., and Davis, J.G. (1977) Aerosol growth studies-II. Preparation and growth measurements of monodisperse salt aerosols. L. Aerosol Sci. 8:149-159.

Tapia, M.S., Stella, M.A., and Chirife, J. (2007) Effects of water activity (aw) on microbial stability: as a hurdle in food preservation. In Water Activity in Foods: Fundamentals and Applications, edited by G.V. Barbosa-Canovas, A.J. Fontana, S.J. Schmidt, and T.P. Labuza, Institute of Food Technologists and Blackwell Publishing, Ames, IA, pp 239-271.

Warren-Rhodes, K.A., Rhodes, K.L., Pointing, S.B., Ewing, S.A., Lacap, D.C., Gomez-Silva, B., and McKay, C.P. (2006) Hypolithic cyanobacteria, dry limit of photosynthesis, and microbial ecology in the hyperarid Atacama Desert. Microb. Ecol. 52:389-398.

Wierzchos, J., Ascaso, C., and McKay, C.P. (2006) Endolithic cyanobacteria in halite rocks from the hyperarid core of the Atacama Desert. Astrobiology 6:415-422.

Williams, J.P. and Hallsworth, J.E. (2009) Limits of life in hostile environments: no barriers to biosphere function? Environ. Microbiol. 11:3294-3308.

Wise, M.E., Martin, S.T., Russell, L.M., and Buseck, P.R. (2008) Water uptake by $\mathrm{NaCl}$ particles prior to deliquescence and the phase rule. Aerosol. Sci. Technol. 42:281-294.

Zorzano, M.P., Mateo-Martí, E., Prieto Ballesteros, O., Osuna, S., and and Renno N. (2009) Stability of liquid saline water on present day Mars. Geophys. Res. Lett. 36, doi:10.1029/2009GL040315.

Address correspondence to: Alfonso F. Davila SETI Institute 514 Wishman Road Mountain View, CA

E-mail: adavila@seti.org

Submitted 25 August 2009 Accepted 21 April 2010 
This article has been cited by:

1. Alberto G. Fairén, Alfonso F. Davila, Darlene Lim , Nathan Bramall, Rosalba Bonaccorsi , Jhony Zavaleta , Esther R. Uceda , Carol Stoker, Jacek Wierzchos, James M. Dohm, Ricardo Amils, Dale Andersen, Christopher P. McKay . 2010. Astrobiology through the Ages of Mars: The Study of Terrestrial Analogues to Understand the Habitability of MarsAstrobiology through the Ages of Mars: The Study of Terrestrial Analogues to Understand the Habitability of Mars. Astrobiology 10:8, 821-843. [Abstract] [Full Text] [PDF] [PDF Plus]

2. Alfonso F. Davila, Mark Skidmore, Alberto G. Fairén, Charles Cockell, Dirk Schulze-Makuch . 2010. New Priorities in the Robotic Exploration of Mars: The Case for In Situ Search for Extant LifeNew Priorities in the Robotic Exploration of Mars: The Case for In Situ Search for Extant Life. Astrobiology 10:7, 705-710. [Citation] [Full Text] [PDF] [PDF Plus]

3. Alfonso F DavilaAstromicrobiology . [CrossRef] 